\title{
A LITERATURA E O LIVRO DIDÁTICO: UMA ANÁLISE DAS RELAÇÕES INTERMIDIÁTICAS
}

\author{
Bonfim Queiroz Lima* \\ Márcio Araújo de Melo \\ Universidade Federal do Tocantins
}

\begin{abstract}
Resumo: Este trabalho procura analisar, na perspectiva dos estudos interartes, quais relações são estabelecidas entre literatura e as outras linguagens artísticas no âmbito do ensino escolar, realizando a análise de capítulos que abordam os conteúdos de literatura e compõem os livros didáticos de língua portuguesa. Utilizou-se metodologia de análise documental. Procura-se, a princípio, definir o viés de estudo dessas relações a partir de pressupostos teóricos relacionados à intermidialidade, um campo de pesquisa, relativamente novo, que faz parte dos estudos interartes. Logo depois realiza a análise de amostras de capítulos de dois manuais didáticos de ensino médio, tentando identificar nestas obras quais são as relações estabelecidas entre as ocorrências de linguagens verbais e não verbais e as outras mídias. O manual analisado foi adquirido pelo Governo Federal por intermédio do Ministério da Educação, através do Programa Nacional do Livro Didático - PNLD - e distribuído para escolas públicas de todo país. Portanto segue uma série de normas técnicas e didáticas, que estão listadas no edital de convocação para inscrição no processo de avaliação deste programa; entre essas normas didáticas encontrasse a orientação para o favorecimento da convivência do estudante com diferentes representações de linguagem e para uma abordagem interdisciplinar e global dos conteúdos e das habilidades abrangidas pelos manuais. Como resultados pode-se citar que há uma busca por parte dos autores desses manuais em cumprir tais orientações, no entanto, essas tentativas carecem de aprimoramento.
\end{abstract}

Palavras-chave: Ensino de Literatura. Estudos Intermidiáticos. Livro Didático.

Esta obra está licenciada sob uma Creative Commons - Atribuição 4.0

\footnotetext{
* Possui graduação em Letras pela Universidade Federal do Pará (2003), especialização em Língua Portuguesa: Uma Abordagem Textual pela Universidade Federal do Pará (2005), Mestrado em Letras: Ensino de Língua e Literatura pela Universidade Federal do Tocantins (2014) e atualmente é doutoranda em Letras também pela Universidade Federal do Tocantins. Participa do Grupo de Estudos e Pesquisas sobre Leitura, Escrita e Livros (GEPLEL) UFU/CNPq, coordenado pela Profa. Dra. Karina Klinke e pelo Prof. Dr. Márcio Araújo de Melo. É Professora de Língua Portuguesa junto a SEDUC - PA e a SEMED - Xinguara - PA. Tem experiência na área de Letras, com ênfase em Ensino de Literatura e Literatura Brasileira. E-mail: bonfimql@,hotmail.com

** Graduado em Letras - Habilitação Português pela Universidade Federal de Goiás (1993), Mestre em Letras e Linguística pela Universidade Federal de Goiás (1997) e Doutor em Estudos Literários pela Universidade Federal de Minas Gerais (2006). Segundo Líder do Grupo de Estudos e Pesquisas em Leitura, Escrita e Literatura: história, políticas e ensino (GEPLEL). Coordenador do ProfLetras (Mestrado profissional em Letras). Professor do programa de pós-graduação em Ensino de Língua e Literatura, da Universidade Federal do Tocantins. Tem experiência na área de Letras, com ênfase em Literatura Brasileira, atuando principalmente nos seguintes temas: escolarização da literatura, Guimarães Rosa e literatura comparada. E-mail: marciodemelo33@gmail.com
} 


\section{Considerações iniciais}

A orientação de um trabalho interdisciplinar, envolvendo as diferentes linguagens, é recorrente nos documentos oficiais. No entanto, estas mesmas orientações reconhecem que o ensino de literatura se desenvolve de maneira não satisfatória, pois acontece a substituição da literatura considerada mais complexa por uma mais "digerível”, por resumos e paráfrases ou reduz-se o seu ensino apenas a informações externas às obras e aos textos. Ainda, segundo os documentos oficiais, um dos maiores responsáveis por esse modelo de ensino é o livro didático:

Esse quadro geral de deslocamentos só será revertido se se recuperar a dimensão formativa do leitor, em processo iniciado no ensino fundamental, que, no ensino médio, se perde em objetivos pragmáticos, formulados, sobretudo, nos manuais didáticos, que, mais para o mal que para o bem, vêm tradicionalmente cumprindo o papel de referência curricular para esse nível da escolaridade (BRASIL, 2006, p. 64).

Essa afirmação trazida nas OCEM é corroborada por outros estudiosos da área como Rangel (2007), ao afirmar que, muitas vezes, o aprendizado da leitura e da escrita na escola fica restrito totalmente ao livro didático tornando-se, para muitos alunos, parâmetro para a definição do que seja uma "boa leitura". Por conseguinte está incluindo neste rol o acesso ao texto literário:

[...] para muitos dos brasileiros escolarizados, o LD tem sido o principal ou o exclusivo meio de acesso ao mundo da escrita. E o LDP, com suas atividades de estudo de texto, o instrumento por excelência de aprendizagem da leitura e de concepção do que deva ser uma "boa” leitura (RANGEL, 2007, p.131).

Diante da grande influência do manual didático no ensino e Língua Portuguesa e, consequentemente, no ensino de Literatura, resolveu-se tomá-lo como objeto de análise, para verificar como se desenvolve nestas obras as relações entre a literatura e as outras linguagens artísticas.

\section{Literatura e outras artes}

As relações existentes entre a literatura e as outras linguagens artísticas datam de tempos remotos. Na Era Clássica, a encenação de peças teatrais, na Grécia Antiga, já era indício do estabelecimento dessas relações, uma vez que eram representações de textos dramáticos. Na Idade Média, já encontrávamos as iluminuras integrando-se ao texto verbal de tal forma que seria impossível separá-los. São dessa mesma época as tão estudadas "cantigas medievais" que muito contribuíram para a constituição do que conhecemos hoje como poema. 
No entanto, esta relação existente entre as outras artes e a literatura tem raízes ainda mais remotas, pois, na maioria das civilizações antigas, as imagens auxiliavam ou serviam para contar as narrativas (reais ou fictícias) de cada povo. Um exemplo muito difundido desta relação pode ser encontrado nas inscrições egípcias, esculpidas nas paredes das pirâmides e catacumbas, onde existe a integração entre as imagens e os hieróglifos.

Nos estudos literários, houve épocas em que essas relações chegaram a ser negadas, na medida em que se tentou estudar literatura apenas por seus aspectos "intrínsecos". Tal vertente foi defendida e amplamente divulgada por Wellek e Warren (2003) em seu livro Teoria da literatura e metodologia dos estudos literários (publicado originalmente em inglês, em 1949, com o título Theory of literture). Para esses autores, o texto literário possui um mundo próprio, autônomo e autossuficiente. O estudo do que é "extrínseco" ao texto, como sua relação com a sociedade, história, psicologia, política, biografia e inclusive sua relação com as outras artes, segundo Wellek, é de valor questionável (CLÜVER, 1997).

Esse distanciamento nos estudos literários em relação às outras artes reflete uma relação complexa que se estabeleceu entre os escritores e demais artistas, principalmente em relação aos artistas plásticos, já que, durante séculos, foram considerados socialmente inferiores àqueles e, em outra conjuntura, estas relações sociais se inverteram, como nos mostra Mello (2004, p. 09): “A França, do século XVII ao século XIX, confere à Literatura um estatuto superior ao da Pintura. Em um dado momento, entretanto, os papéis parecem inverte-se e a pintura passa a servir de modelo à literatura". Para a autora, um dos fatos consolidadores desta transformação foi a fundação da Real Academia de Pintura e Escultura apoiada por Luís XVI. Na atualidade, as relações estabelecidas entre as diversas linguagens artísticas são estudadas a partir de inúmeras vertentes.

Quando o enfoque é o ensino escolar, verifica-se que não é novidade realizar uma abordagem de maneira interdisciplinar ou transdisciplinar, uma vez que essas perspectivas já vêm orientando o ensino brasileiro ${ }^{1}$ há alguns anos. No ensino de Língua Portuguesa não poderia ser diferente, uma vez que toma o texto como objeto de ensino. Portanto, os conceitos de intertextualidade e de transtextualidade se tornam inerentes ao ensino escolar dessa disciplina, já que este é "tudo que coloca [o texto] em relação, manifesta ou secreta com outros textos" (GENETTE, apud BARROS, 2006, p. 125) e aquele é defino de forma "restritiva, como uma relação de co-presença entre dois ou vários textos, isto é, essencialmente, e o mais frequentemente, como presença efetiva de um texto em um outro."

\footnotetext{
${ }^{1}$ Mesmo que em algumas escolas estas orientações apareçam apenas teoricamente.
} 
(GENETTE, apud BARROS, 2006, p. 125). Por conseguinte, se verifica que, no ensino de literatura, parece ser constituinte o caráter interdisciplinar à natureza de textos literários, haja vista a variedade de gêneros existentes e que cada texto pode englobar uma diversidade inumerável de matérias.

\section{A intermidialidade e os estudos interartes}

Procura-se, neste capítulo, realizar a análise de livros didáticos de Língua Portuguesa do Ensino Médio baseando-se no conceito de signos ou textos intermídias, que junto com os conceitos de textos multimídias e mixmídias fazem parte dos estudos da intermidialidade, um campo transdisciplinar relativamente novo que está se estabelecendo e que, segundo Clüver (2008, p. 210), “[...] incorpora as tradições dos Estudos Interartes e as discussões a respeito dentro das disciplinas dos Estudos das Mídias ('Media Sudies') e também as investigações mais recentes sobre as 'poesias das Mídias Novas' ('New Medias Poetries') baseados nas mídias digitais".

O mesmo autor nos explica que a comparação entre as artes tem uma longa história que remonta à antiguidade clássica, mas que somente a partir do século passado é que começaram a ser produzidos os primeiros estudos acadêmicos sérios e influenciadores que tratavam das inter-relações entre as artes e esclarece, ainda, que:

A necessidade de reconhecer os Estudos Interartes como "Estudos da Intermidialidade" ou "Estudos intermidiáticos" surgiu tanto da percepção de que havia acontecido uma gradativa mudança na orientação teórica e nas práticas do discurso interdisciplinar quanto da aproximação entre as áreas dos Estudos Interartes e dos Estudos das Mídias (CLÜVER, 2008, p. 212).

Clüver (2008), em seu artigo "Intermidialidade e Estudos interartes", traz um esquema sistemático das relações entre palavras e imagem na transposição intermidiática e nos tipos de conexão existentes entre as mídias, considerando seus aspectos de produção, recepção, separabilidade, tipo de relação, coerência e politextualidade. Além de considerar estes aspectos, traz também exemplos de cada um. Tal esquematização foi reproduzida a seguir: 
Quadro 1: Esquema de relações palavra-imagem.

\begin{tabular}{|c|c|c|c|c|}
\hline $\begin{array}{c}\text { Esquema de } \\
\text { relações palavra- } \\
\text { imagem }\end{array}$ & $\begin{array}{c}\text { Relação } \\
\text { transmidiática }\end{array}$ & $\begin{array}{c}\text { Discurso } \\
\text { multimídia }\end{array}$ & $\begin{array}{l}\text { Discurso } \\
\text { mixmídia }\end{array}$ & $\begin{array}{c}\text { Discurso } \\
\text { intermídia/ } \\
\text { intersemiótico }\end{array}$ \\
\hline Separabilidade & + & + & + & - \\
\hline $\begin{array}{l}\text { Coerência/ } \\
\text { auto-suficiência }\end{array}$ & + & + & - & - \\
\hline Politextualidade & + & - & - & - \\
\hline $\begin{array}{l}\text { Produção } \\
\text { simultânea }\end{array}$ & - & - & + & + \\
\hline $\begin{array}{l}\text { Recepção } \\
\text { simultânea }\end{array}$ & - & + & + & + \\
\hline Tipo de relação & transposição & justaposição & combinação & União/fusão \\
\hline $\begin{array}{c}\text { Relação } \\
\text { esquematizada }\end{array}$ & $\begin{array}{l}\text { texto }>\text { imagem } \\
\text { imagem }>\text { texto }\end{array}$ & $\begin{array}{l}\text { Imagem } \\
\text { texto }\end{array}$ & $\begin{array}{c}\text { Imagem }+ \\
\text { texto }\end{array}$ & itmeaxgteom \\
\hline Exemplos & $\begin{array}{c}\text { ecfrase } \\
\text { crítica de arte } \\
\text { fotonovela }\end{array}$ & $\begin{array}{c}\text { emblema } \\
\text { livro } \\
\text { ilustrado } \\
\text { pintura \& } \\
\text { título }\end{array}$ & $\begin{array}{c}\text { cartaz } \\
\text { história em } \\
\text { quadrinhos } \\
\text { selo postal }\end{array}$ & $\begin{array}{c}\text { tipografia } \\
\text { caligrafia } \\
\text { poesia } \\
\text { concreta }\end{array}$ \\
\hline
\end{tabular}

Fonte: (VOS, apud CLÜVER, 2008, p. 219).

$\mathrm{Na}$ esquematização reproduzida, há uma clara diferenciação das relações estabelecidas entre as possibilidades de manifestações artísticas. Pode-se, então, considerar que:

- A relação transmidiática ocorre de diferentes formas entre diferentes mídias, como a representação verbal de textos compostos em sistemas não verbais, a recriação de um texto como autossuficiente numa outra mídia ou num outro sistema sígnico, a ecfrase, etc assim textos verbais podem ser transpostos ou adaptados em imagens, composições musicais, filmes e vice-versa.

- Um texto multimídia combina textos separáveis e coerentes individualmente e que são compostos por mídias diferentes - como um texto que contenha gravuras apenas para sua ilustração.

- Um texto mixmídia é composto por signos complexos em mídias diferentes que não se tornariam autossuficientes fora de seu contexto original - caso da história em 
quadrinhos em que a parte visual e verbal se complementam, podendo até serem separados, mas se ocorrer tal separação ficariam incoerentes.

- Um texto intermídia ou intersemiótico é composto por mais de uma mídia, de tal forma que os aspectos desses sistemas de signos se tornam inseparáveis - um exemplo desse tipo de texto são os poemas concretos, em que os aspectos visuais e verbais não são divisíveis.

Tendo esclarecido como são delineadas as relações que se estabelecem entre as artes na perspectiva dos estudos transmidiáticos, o que se fará a partir deste ponto é tentar estabelecer como tais relações são tratadas ou retratadas no âmbito educacional, mais especificamente no ensino de literatura no ensino médio.

\section{O livro didático: uma análise intermidiática}

Sabendo que o Governo Federal, por intermédio do Ministério da Educação, adquire através do Programa Nacional do Livro Didático - PNLD - obras didáticas que são distribuídas para escolas públicas de todo o país, e que, para se inscreverem neste programa, os livros devem seguir uma série de normas técnicas e didáticas que estão listadas no edital de convocação para inscrição do processo de avaliação e, sabendo ainda que, entre essas normas está a deliberação de que os manuais didáticos devem "favorecer a convivência do aluno com diferentes representações de linguagem, com diferentes modalidades de tipos e gêneros de textos, de épocas, regiões, funções, registros diversificados" (BRASIL, 2009, p. 23) e que devem promover "uma abordagem interdisciplinar e global dos conteúdos e das habilidades exploradas" (BRASIL, 2009, p. 23), optou-se pela análise de uma obra aprovada por este programa.

Dessa forma, escolhemos a coleção "Português Linguagens: literatura - produção de texto - gramática" (5a edição, 2005), de William Roberto Cereja e Thereza Cochar Magalhães e que seria comparada com outro livro didático, dos mesmos autores, intitulado "Literatura Brasileira: em diálogo com outras literaturas e outras linguagens" ( $3^{\mathrm{a}}$ edição, 2005), ambos da editora Atual.

O trabalho inicialmente pensado, no entanto, se tornou inviável, uma vez que, ao se adquirir o segundo título, observou-se que as duas obras eram parcialmente idênticas; pois os capítulos dedicados à literatura presentes na coleção Português Linguagens - composta de três volumes, correspondentes às três séries do ensino médio - foram integralmente reproduzidos no livro Literatura Brasileira. Desta forma, este livro corresponde, apenas, a união do conteúdo de literatura presente na coletânea. 
Optou-se, então, por uma questão de praticidade, pela análise do livro Literatura Brasileira, entendo que, ao analisá-lo, contemplam-se os capítulos de literatura presentes na coletânea do mesmo autor. Seguindo uma organização histórico cronológica, o livro utiliza-se da clássica nomenclatura das escolas literárias e está dividido em doze unidades que englobam cinquenta e oito capítulos, sendo que a primeira unidade - os cinco primeiros capítulos - tratam da definição do que é literatura e de suas funções, além da diferenciação entre gêneros e estilos literários.

Como o próprio título sugere, o livro, em suas quinhentas e setenta e seis páginas, estabelece inúmeras relações entre a literatura e as outras linguagens artísticas, principalmente nas doze seções denominadas "Intervalo" em que são apresentadas propostas de projetos interdisciplinares abordando os temas tratados nos capítulos antecedentes. Destaca-se, ainda, no estabelecimento destas relações a seção "Fique ligado! Pesquise!" que se localiza no início de cada unidade, onde se encontram sugestões de filmes, livros, músicas, artes plásticas, sites, entre outras fontes de pesquisa, que poderão ampliar o conhecimento dos alunos sobre o tema abordado na unidade.

Vale ressaltar que as seções "Intervalo" e "Fique ligado! Pesquise!", presentes nesta obra, buscam atender aos requisitos do edital do PNLD 2012 - Ensino Médio que, corroborando com os documentos oficiais, observa, como critério eliminatório, se o manual didático de Língua Portuguesa: "incentiva a busca de informações em outros livros, suportes e materiais (como filmes, sites e outros recursos da internet etc.); [...] promove uma abordagem interdisciplinar e global dos conteúdos e das habilidades exploradas” (BRASIL, 2009, p. 24).

Tomando como referência o quadro 1, que propõe uma classificação para as relações que se estabelecem entre as manifestações artísticas, analisou-se as imagens presentes nos treze primeiros capítulos do mesmo manual e chegou-se ao seguinte resultado:

Tabela 1: Relação: verbal - não verbal /capítulos 1 a 13

Relação: verbal - não verbal / capítulos 1 a 13

\begin{tabular}{|l|c|c|}
\multicolumn{1}{|c|}{ Descrição } & Ocorrência & Porcentagem \\
\hline Relação transmidiática & 06 & $4 \%$ \\
\hline Discurso multimídia & 124 & $84 \%$ \\
\hline Discurso mixmídia & 14 & $10 \%$ \\
\hline Discurso intermídia & 00 & $0 \%$ \\
\hline Mídia diversa sem relação & 03 & $2 \%$ \\
\hline Total & 147 & $100 \%$ \\
\hline
\end{tabular}

Fonte: Dados da pesquisa. 


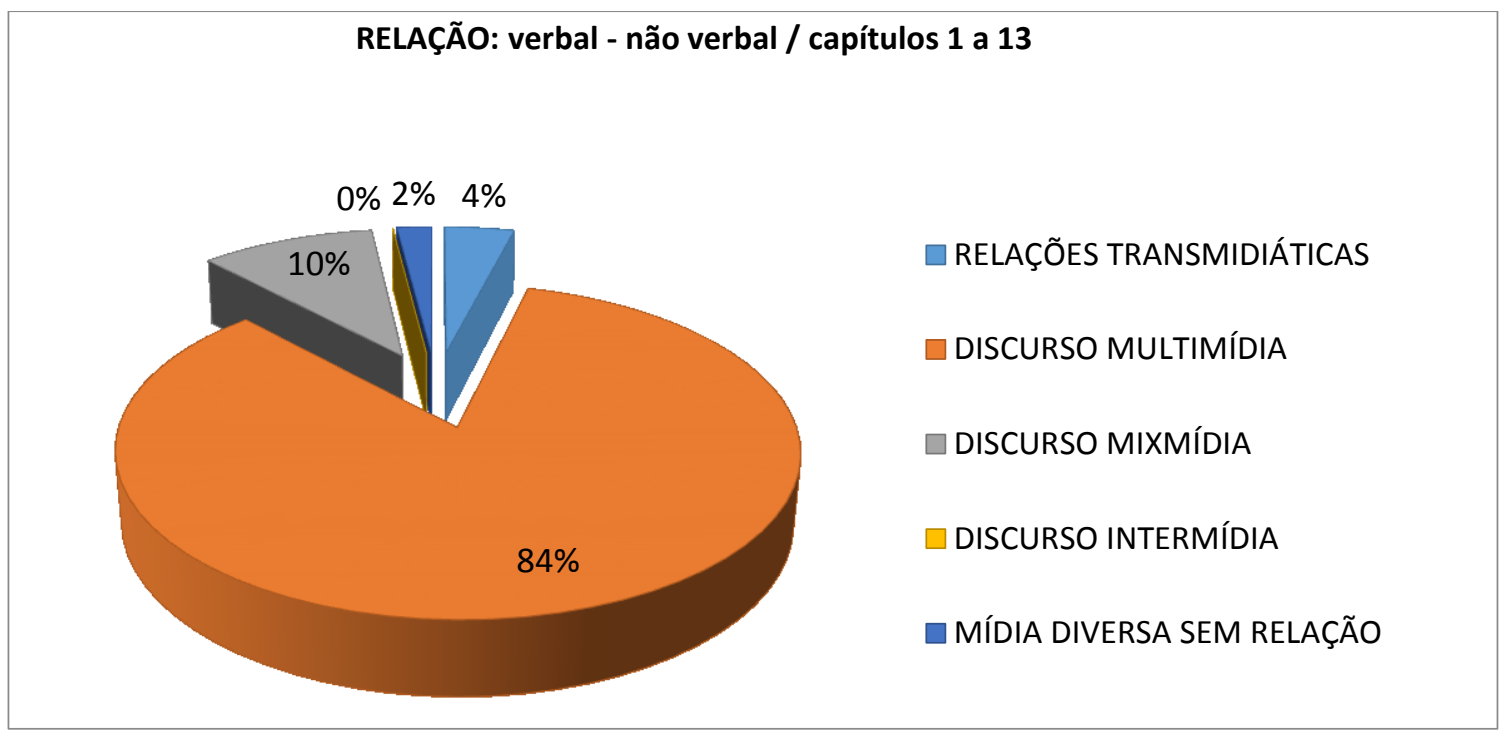

Fonte: Dados da pesquisa.

Conforme tabela 1 e gráfico 1 , a prevalência das relações estabelecidas entre as imagens presentes no livro e os textos verbais, nos referidos capítulos, é de justaposição, ou seja, o discurso multimídia, na maioria das ocorrências, são apenas imagens ilustrativas para os textos, atividades ou o início do capítulo ou unidade. Algumas dessas imagens são representativas do período literário que está sendo abordado (como "Trovadores" em uma iluminura do manuscrito medieval "As cantigas", de Alphonse Le Sage, p. 79). Outras são apenas gravuras relacionadas ao tema tratado no texto e em alguns casos não são referendadas as fontes, fincando implícito que elas foram criadas apenas para compor a obra em análise (como a imagem que ilustra os poemas "O 'adeus' de Teresa", de Castro Alves, e "Teresa", de Manuel Bandeira, p. 68).

Além das gravuras, aparecem também, estabelecendo uma relação de justaposição com os textos, imagens de fotografias de esculturas, de telas e de obras arquitetônicas (como as ruínas do teatro de Herodes, em Atenas, Grécia, p. 29). As imagens que foram consideradas como discurso mixmídia reproduzem capas de livros, discos e CDs, cartazes de peças teatrais e filmes - em que há relação de combinação entre os elementos verbais e não verbais - além das histórias em quadrinhos.

As relações transmidiáticas manifestam-se de diferentes formas, como na transposição do quadro "A Mona Lisa", de Leornardo da Vinci, para duas outras imagens, o quadro "L.H.O.O.Q", de Marcel Duchamp e para um anúncio publicitário, veiculado na revista Claudia (CEREJA; MAGALHÃES, 2005, p. 45); ou como na transposição da peça 
teatral "Auto da compadecida", de Ariano Suassuna, para a minissérie de TV, também com mesmo nome, no livro temos um fragmento do texto dramático e a imagem de uma cena da minissérie (p. 63).

Denominou-se "mídia diversa sem relação", a análise de obras não literárias que são realizadas no decorrer dos capítulos do livro, englobando filmes e telas famosas que são representativos dos períodos artísticos estudados, mas que não apresentam relação intermidiática com os textos veiculados no capítulo em que se inserem, como a análise do quadro "Experiência com uma bomba de ar", de Joseph Wright (CEREJA; MAGALHÃES, 2005, p. 153).

O discurso intermídia ou intersemiótico se caracteriza pela fusão entre os elementos verbais e não verbais; nos capítulos analisados não há a presença dessa categoria específica. Entretanto, ele aparece em outras passagens do livro, como na reprodução dos poemas concretos de Guillaume Apollinaire, de Augusto de Campos, de Paulo Leminski e de Arnaldo Antunes (CEREJA; MAGALHÃES, 2005, p. 433 e 434).

Sabendo que algumas categorias desta análise surgem de forma distinta ao longo da apresentação do conteúdo no manual de Cereja e Magalhães (2005) e que ele é organizado de forma cronológica, com base na tradicional divisão das escolas literárias, decidiu-se por realizar a análise de uma segunda amostra que englobasse períodos diferentes dos já examinados. Assim, a segunda amostra foi composta pelos capítulos 19, 20, 21 (p. 201 a 224), 29, 30, 31, 32 e 33 (p. 297 a 337) do mesmo livro didático.

Tabela 2: Relação: verbal - não verbal / Comparação entre amostras

\begin{tabular}{|l|c|c|c|c|}
\hline \multicolumn{5}{|c|}{ Relação: verbal - não verbal / comparação entre amostras } \\
\hline \multirow{2}{*}{ Descrição } & \multicolumn{2}{c|}{ Cap. 1 a 13 } & \multicolumn{2}{c|}{ Cap. 19 a 21 - 29 a 33 } \\
\cline { 2 - 5 } & Ocorrência & Porcentagem & Ocorrência & Porcentagem \\
\hline Relação transmidiática & 06 & $4 \%$ & 13 & $16 \%$ \\
\hline Discurso multimídia & 124 & $84 \%$ & 68 & $81 \%$ \\
\hline Discurso mixmídia & 14 & $10 \%$ & 02 & $2 \%$ \\
\hline Discurso intermídia & 00 & $0 \%$ & 00 & $0 \%$ \\
\hline Mídia diversa sem relação & 03 & $2 \%$ & 01 & $1 \%$ \\
\hline Total & 147 & $100 \%$ & 84 & $100 \%$ \\
\hline
\end{tabular}

Fonte: Dados da pesquisa 


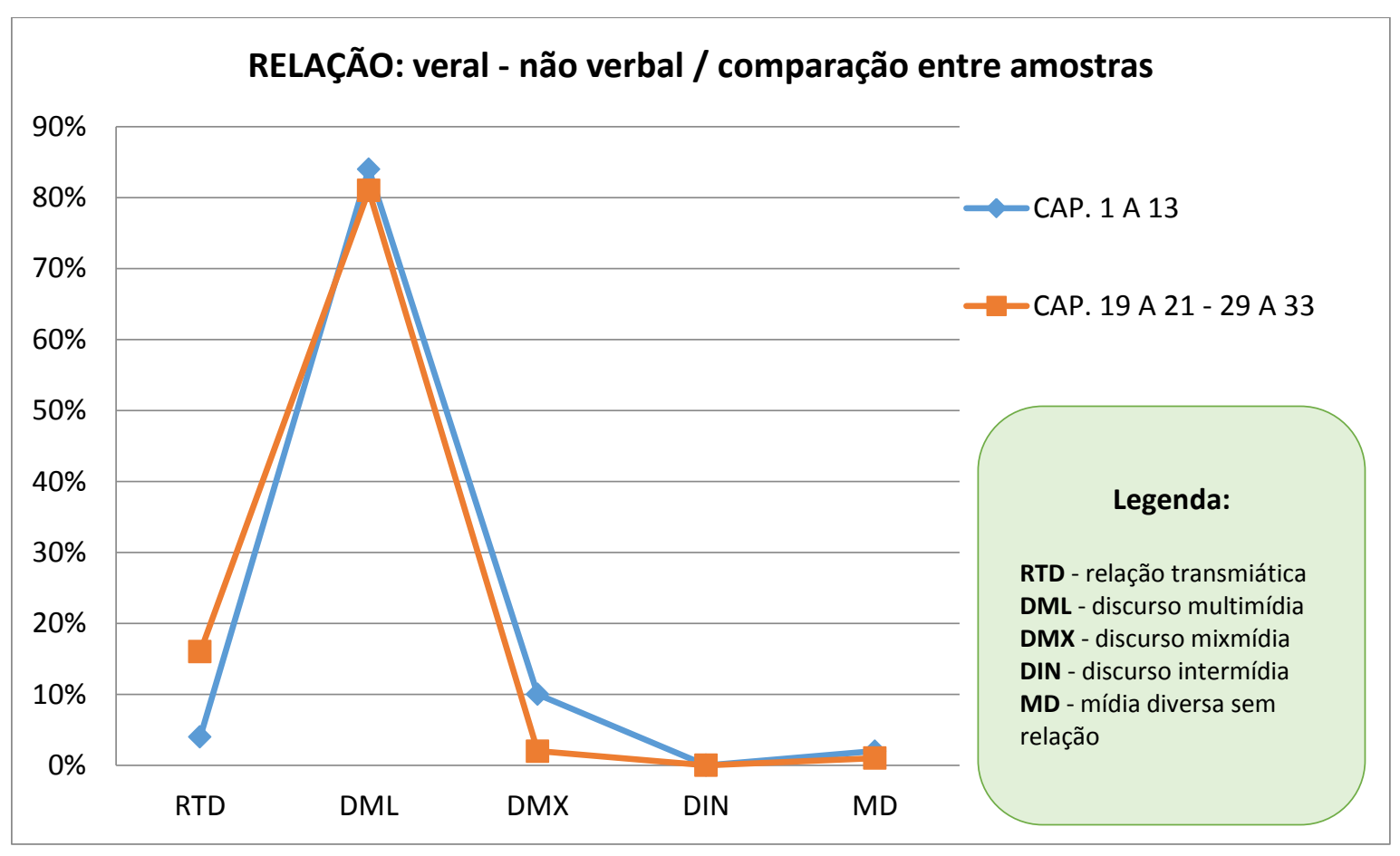

Fonte: Dados da pesquisa

Observa-se na tabela 2 e no gráfico 2 , que a mudança no conteúdo abordado em cada amostra analisada não influencia de maneira significativa as relações que se estabelecem entre os elementos verbais e não verbais que compõem a obra estudada, uma vez que a alteração percentual que foi vislumbrada difere pouco entre as amostras e há relação de proporção entre as ocorrências, permanecendo a maior incidência das relações multimidiáticas.

Com o intuito de comparar a ocorrência observada no livro didático em análise, buscou-se realizar a análise de outra obra. Logo, elegeu-se o segundo volume da coleção "Português: literatura, gramática, produção de texto", de LeilarLauar Sarmento e Douglas Tufano (2010), ainda em sua primeira edição, para averiguar se haveria discrepância ou semelhança entre os dados.

Visando a sistematização dos dados, convencionou-se nomear o livro de Cereja e Magalhães de manual "A" e o livro de Sarmento e Tufano de manual "B", sendo que da primeira obra manteve-se a análise realizada na segunda amostra, dos capítulos 19, 20, 21 (p. 201 a 224), 29, 30, 31, 32 e 33 (p. 297 a 337), sendo que os primeiros tematizam a poesia do período do Romantismo e os últimos abordam o Realismo, Parnasianismo e o Simbolismo. Buscando, então uma aproximação maior entre os temas selecionou-se do manual "B" os capítulos 5 (p. 102 a 129) e 7 (p. 153 a 193), que abordam respectivamente a poesia do Romantismo no Brasil e o Realismo no Brasil. A diferença entre a quantidade de capítulos 
selecionados se justifica pela divergência na divisão e seleção de conteúdos em cada manual, procurou-se uma aproximação entre conteúdos e quantidade de páginas, assim foram analisadas do manual "A" sessenta e três laudas e do manual "B" sessenta e sete laudas.

Tabela 3: Relação: verbal - não verbal / Análise comparativa entre manuais

\begin{tabular}{|l|c|c|c|c|}
\hline \multicolumn{5}{|c|}{ Relação: verbal - não verbal/ análise comparativa entre manuais } \\
\hline \multicolumn{1}{|c|}{ Manual } & \multicolumn{2}{|c|}{ A } & \multicolumn{2}{c|}{ B } \\
\hline \multicolumn{1}{|c|}{ Descrição } & Ocorrência & Porcentagem & Ocorrência & Porcentagem \\
\hline Relação transmidiática & 13 & $16 \%$ & 03 & $5 \%$ \\
\hline Discurso multimídia & 68 & $81 \%$ & 43 & $75 \%$ \\
\hline Discurso mixmídia & 02 & $2 \%$ & 10 & $18 \%$ \\
\hline Discurso intermídia & 00 & $0 \%$ & 01 & $2 \%$ \\
\hline Mídia diversa sem relação & 01 & $1 \%$ & 00 & $0 \%$ \\
\hline Total & 84 & $100 \%$ & 57 & $100 \%$ \\
\hline
\end{tabular}

Fonte: Dados da pesquisa

Observa-se que as relações estabelecidas entre as palavras e imagens nas amostras analisadas dos dois manuais matêm uma proporção relativamente semelhante. A prevalência é do discurso multimídia e ambos apresentam ausência ou presença ínfima do discurso intermídia e da análise de outra linguagem não literária. Destaca-se também nestas amostras a maior quantidade de ocorrências encontradas no manual " $\mathrm{A}$ " (manual " $\mathrm{A}$ " = 84 e manual "B" $=57$ ocorrêmcias), mesmo tendo sido analidas uma quantidade menor de páginas (manual "A" $=63$ e manual "B" $=67$ páginas $)$.

Apesar da aparente semelhança quanto a presença das relações multimidiáticas nas duas obras, é necessário destacar que, em grande parte das ocorrências, no manual "B", as imagens que apresentaram essas relações eram apenas gravuras ilustrativas das páginas ou textos; enquanto, no manual "A”, essas gravuras criadas apenas para ilustrar a página ou texto aparecem em quantidade mínima. A maioria das imagens que estabelecem essa relação são cenas de filmes ou peças teatrais, quadros, fotografias de cantores ou bandas - inclusive acompanhadas de letras de canções - estátuas e monumentos arquitetônicos.

A maior disparidade encontrada refere-se à relação transmidiática e ao discurso mixmídia, sendo que este é mais frequente no manual "B", manifestando-se sobretudo em imagens de cartazes, capas de livros e DVDs de filmes, e aquelas são mais frequentes no manual "A", estabelecendo-se principalmente na presença de imagens que exibem adaptações de textos literários para filmes, peças teatrais e minisséries, como nas imagens que mostram cenas do filme "Os miseráveis" e do musical com o mesmos nome (p. 218). 


\section{Considerações finais}

As relações que existem entre as diferentes linguagens artísticas são evidentes e, como já foi discutido, datam de tempos remotos, são inerentes à construção cultural de todas as sociedades. Por isso, não podem se apresentar no processo de ensino-aprendizagem de forma diferente, ou seja, estas relações devem ser preservadas no decorrer da constituição do conhecimento a ser escolarizado.

Pode-se afirmar, a partir dos resultados obtidos, que os manuais didáticos aqui analisados, apesar das limitações impostas pelo próprio meio de veiculação, procuram contemplar as orientações advindas tanto nos documentos oficiais quanto no edital do PNLD. Como exemplo da busca por um trabalho interdisciplinar, temos a presença na obra de Cereja e Magalhães das cessões "Intervalo", "Fique ligado! Pesquise!” e "A imagem em foco" e no manual de Sarmento e Tufano a cessão "Vale a pena".

Entretanto, pela observação dos mesmos dados, podemos afirmar também que a busca pela articulação entre as linguagens artísticas, nos manuais didáticos, necessita de maiores investigações que busquem averiguar as disparidades existentes nas ocorrências das relações, que foram constatadas neste capítulo, como também, aprimorar a presença dessas mesmas relações nos manuais didáticos, uma vez que elas proporcionam a integração entre as diferentes mídias.

\section{Referências}

BARROS, Leila Cristina. Palavras, Sons e Imagens em Cartaz: aspectos de intermidialidade no romance Benjamim, de Chico Buarque, e na adaptação cinematográfica de Monique Gardenberg1.Revista Aletria. Belo Horizonte - MG, FL/UFMG, v. 14, n. 1, p. 122-136, jul.dez., 2006.

BRASIL. Edital de Convocação para Inscrição no Processo de Avaliação e Seleção de Obras Didáticas para o Programa Nacional do Livro Didático PNLD 2012 - Ensino Médio. Brasília: 2009.

. Ministério da Educação, Secretaria de Educação Básica, Departamento de Políticas de Ensino Médio. Orientações Curriculares do Ensino Médio. Volume Linguagens, Códigos e suas Tecnologias. Brasília: MEC/SEB, 2006.

CEREJA, William Roberto; MAGALHÃES, Tereza Cochar. Literatura Brasileira: em diálogo com outras literaturas e outras linguagens. 3 ed. São Paulo: Atual, 2005.

CLÜVER, Claus. Estudos interartes: conceitos, termos, objetivos. In: Literatura e sociedade. São Paulo: FFLCH/USP, n. 2, p. 37-55, 1997. 
Intermedialidade e estudos interartes. In: NITRINI, Sandra. et al. Literatura, artes, saberes. São Paulo: Aderaldo \& Rothschid: ABRALIC, 2008.

MELLO, Celina Maria Moreira de. A literatura francesa e a pintura - ensaios críticos. Rio de Janeiro: 7 Letras/UFRJ, 2004.

RANGEL, Egon de Oliveira. Letramento Literário e Livro Didático de Língua Portuguesa: Os Amores Difíceis. In: PAIVA, A.; EVANGELISTA, A. M.; PAULINO, G.; VERSIANE, G. (orgs). Literatura e letramento: espaços, suportes e interfaces: $\mathrm{O}$ jogo do livro. Belo Horizonte: Ceale; Autêntica, 2007.

SARMENTO, Leilar Lauar; TUFANO, Douglas. Português: Literatura, gramática, produção de texto. Volume 2. São Paulo: Moderna, 2010.

WELLEK, René; WARREN, Austin. Teoria da literatura e metodologia dos estudos literários. Tradução de Luís Carlos Borges. São Paulo: Martins Fontes, 2003.

[Recebido em abril de 2015 e aceito para publicação em junho de 2015]

\section{Literature and the Textbook: An analysis of intermedia relations}

Abstract: This paper analyzes from the perspective of interart studies, which relations are established between literature and other artistic languages in the context of school education, performing the analysis of chapters that approach the literature content and makes up the Portuguese textbooks. It was used document analysis methodology. It was aimed at first, to set the bias of study of these relationships from theoretical assumptions related to intermediality, a search field, relatively new, which is part of interart studies. Soon after it accomplished the analsis of samples of chaptters of two textbooks for high school, trying to identify in these works which are the relations set between the instances of verbal and nonverbal languages and other media. The manual analysed was acquired by the Federal Government through the Ministry of Education, through the Programa Nacional do Livro Didático - PNLD - and distributed to public schools across the country. Therefore follows a series of technical and educational standards, which are listed in the summons letter for the application in the evaluation process of this program; among these teaching standards is found the guidance for the favoring of the student coexistence with different language representations and for a interdisciplinary and global approach of the contents and of the skills covered by the manuals. As results it can be mentioned that there is a search by the authors of these manuals to comply with these guidelines, however, these attempts lack of improvement. Keywords: Literature Teaching. Intermidia Studies. Textbook.

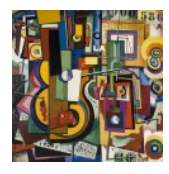

